\title{
Obstrução intestinal por volvo de ceco, relato de caso
}

\section{Obstructions intestinal for cecal volvulus, report case}

Luiz Carlos Maciel ${ }^{1}$; Fernando Oliveira Salán²; Guilherme Costa Guisard²

\section{INTRODUÇÃO}

O volvo de ceco (VC) constitui a principal apresentação das anomalias relacionadas as más rotações intestinais ${ }^{1}$. É caracterizado por torção axial envolvendo o ceco, íleo terminal e cólon ascendente sobre seus respectivos mesos $^{1,2}$, resultando em obstrução intestinal ${ }^{3}$.

A incidência é de 2,8 a 7,1 por milhões de pessoas ano, perfazendo $22 \%$ dos volvos colônicos ${ }^{4}$, ocasionando 1 a 1,5\% das obstruções intestinais em adultos².

Apresenta-se com dor aguda e distensão abdominal, associado a náuseas, vômitos ${ }^{1,4}$, e hipertimpanismo com ou sem massa abdominal palpável².

O objetivo é relatar um caso de VC com ênfase nas suas diferentes condutas diagnósticas e terapêuticas.

\section{RELATO DO CASO}

Sexo feminino, 42 anos, dor abdominal difusa há sete dias, em cólica passando para continua nos últimos três dias, de forte intensidade, acompanhando parada de eliminação de gases e fezes, com vômitos de estase. Havia ausência de operações anteriores. Exame em regular estado geral, descorada, desidratada Grau I, afebril. Abdômen globoso, distendido, ruídos hidro-aéreos aumentados em salvas e timbre metálico, hipertimpânico a percussão, doloroso a palpação em andar superior do abdômen, sem massas palpáveis. Ausência de fezes na ampola retal.

À radiografia foi observada grande distensão de alça intestinal ocupando epigástrio, mesogástrio e hipocôndrio esquerdo (Figuras 1 e 2), e a colonoscopia evidenciou imagem de compressão extrínseca do cólon ascendente não sendo possível a progressão do aparelho além do ângulo esplênico.

Na laparotomia exploradora diagnosticou-se VC e cólon ascendente, estando o ceco na loja esplênica. Na parede cecal havia pontos hemorrágicos e áreas de necrose do mesocólon acima da torção estando a dez centímetros do ângulo hepático (volvo de quatro voltas). Foi realizado colectomia direita com íleotranverso-anastomose látero-terminal.

Paciente evoluiu de forma satisfatória tendo alta no quinto pós-operatório, estando assintomática após sete anos de seguimento ambulatorial.

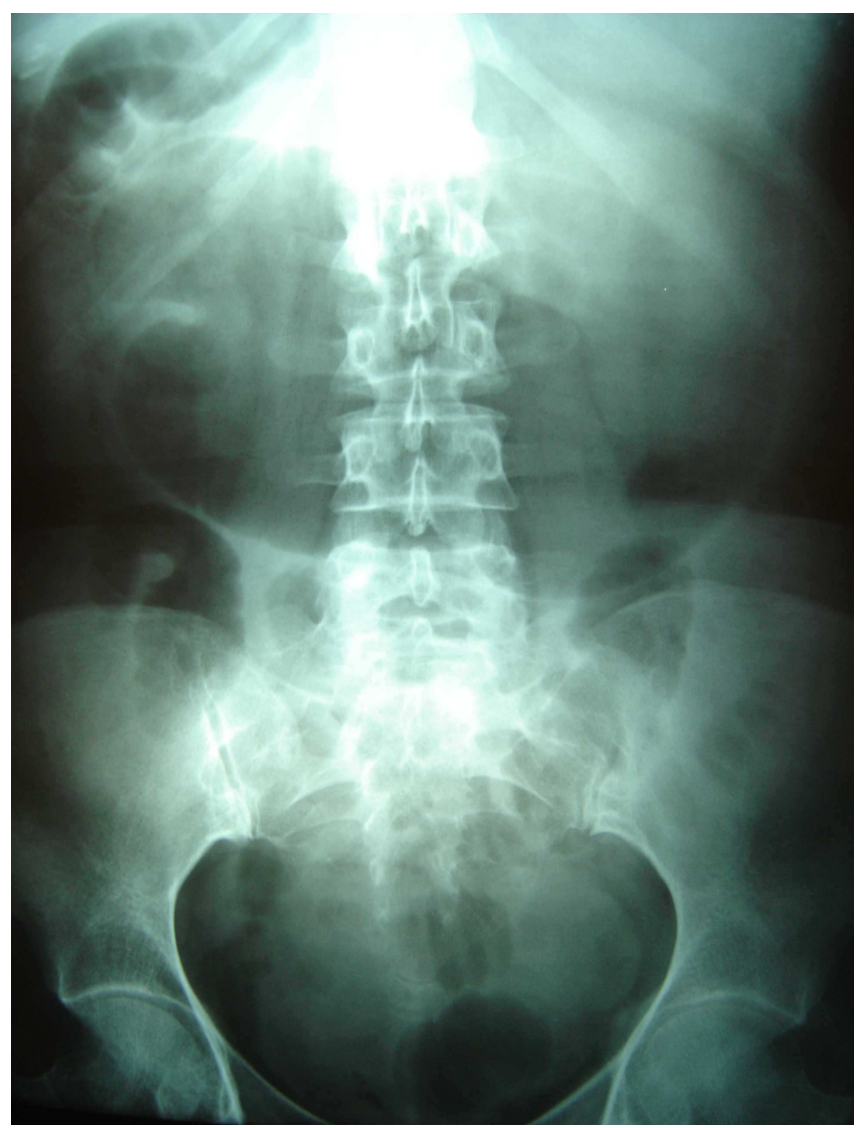

Figura 1 - Distensão do ceco ocupando o andar supra-mesocólico.

\section{DISCUSSÃO}

A má rotação intestinal pode estar associada a duas síndromes distintas envolvendo o ceco: ceco móvel caracterizada por dor abdominal crônica intermitente que melhora espontaneamente com passagem de flatos (esses sintomas são relatados em $50 \%$ destes pacientes), e o próprio VC, que cursa com sintomas de obstrução intestinal aguda que podem evoluir para toxemia, peritonite e morte se não tratado adequadamente ${ }^{2}$.

Para o diagnóstico do VC além do quadro clínico pode-se utilizar um arsenal de exames diagnósticos como: raios-X simples de abdômen, enema opaco, tomografia computadorizada (TC) de abdômen e colonoscopia ${ }^{2,3}$. Nas radiografias simples de abdômen ob-

Trabalho realizado no Hospital Universitário de Taubaté, SP, BR

1. Professor Auxiliar de Ensino da Disciplina de Clínica Cirúrgica da Universidade de Taubaté (UNITAU), SP, BR; 2. Pós-Graduando em Aparelho Digestivo na Faculdade de Medicina da Santa Casa de São Paulo, SP, BR; 3. Residente de Cirurgia Plástica da Santa Casa de Santos, SP, BR. 


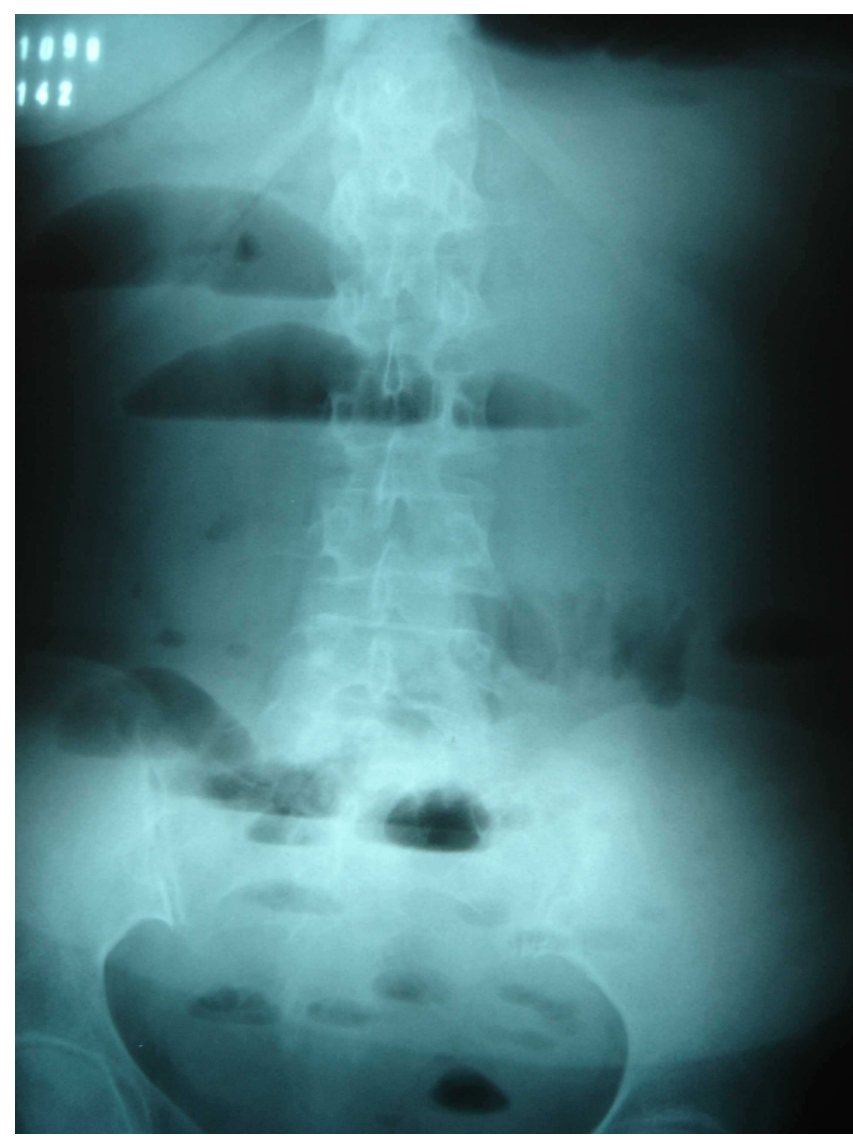

Figura 2 - Nível hidroaéreo no ceco em andar supra-mesocólico. serva-se dilatação do ceco em 98 a 100\% dos casos, ausência de gás no cólon distal, nível líquido e dilatação de delgado ${ }^{2}$, e em alguns casos encontra-se o ceco em posição fora do habitual ${ }^{3}$.

O enema opaco tem sido a modalidade mais tradicionalmente aplicada para confirmação diagnóstica do VC com sensibilidade de $88 \%^{2}$. A TC revela a presença e a localização do volvo, além das complicações como a isquemia e a perfuração, tendo como imagem característica o "olho do redemoinho", composto por círculos espiralados e concêntricos formados pela torção do meso ${ }^{3}$.

A colonoscopia possui bom potencial diagnóstico, pois é capaz de localizar o ponto exato de torção colônica, porém apresenta limitada capacidade terapêutica no VC (variando de 30 a $50 \%$ de sucesso) 3.5 .

As condutas terapêuticas aceitáveis incluem: redução colonoscópica, desvolvulação com cecopexia ou colectomia direita ${ }^{2}$. Havendo pontos hemorrágicos e áreas de necrose acima da torção, optou-se pela colectomia direita e reconstrução primária, estando esta conduta de acordo com a literatura consultada ${ }^{2-4}$. Caso não houvesse sinais de sofrimento vascular no ceco e mesocólon correspondente, poder-se-ia realizar a desvolvulação associada à cecopexia', apesar da recorrência para esta conduta ser de até $70 \%{ }^{2}$.

O VC apesar de pouco freqüente apresenta sinais clínico-radiológicos bem estabelecidos que auxiliam no diagnóstico e intervenção precoce.

\title{
A B S T R A C T
}

\begin{abstract}
Cecal volvulus (CV) establishes the main appearance of the anomalies related to intestinal malrotation. Diagnosis is based on signs and symptoms compatible to intestinal obstructions and complementary examinations as: single radiography form abdomen, opaque enema, computerized tomography and colonoscopy. Therapeutics modalities include: colonoscopy reducing, cecopexy and right colectomy. This article reports a CV case giving emphasis in different diagnosis and therapeutics behaviors.
\end{abstract}

Key words: Cecal diseases/therapy. Intestinal obstruction.

\section{REFERÊNCIAS}

1. Leal Mursulí A, Adefna Pérez RI, Ramos Díaz N, Castellanos González Juan A, Martínez Acosta U, Izquierdo Lara FT. Malrotación intestinal asociada a vóvulo del ciego: reporte de un caso y revisión de la literatura. Rev Cubana Cir. [periódico en la Internet]. 2002 Dic [citado 2009 Feb 20]; 41(4): Disponible en: http://scielo.sld.cu/ scielo.php?script=sci_arttext\&pid=S0034$74932002000400012 \& \operatorname{lng}=e s \& n r m=i s o$.

2. Consorti ET, Liu TH. Diagnosis and treatment of caecal volvulus. Postgrad Med J. 2005; 81(962):772-6.

3. Moore CJ, Corl FM, Fishman EK. CT of cecal volvulus: unraveling the image. AJR Am J Roentgenol. 2001; 177(1):95-8.

4. Wales L, Tysome J, Lim A, Moser S, Tait P, Navarra G. Gastrointestinal: Cecal volvulus. J Gastroenterol Hepatol. 2004; 19(2):225.
5. Theuer C, Cheadle WG. Volvulus of the colon. Am Surg, Mar 1991; vol 57(3): p.145-50.

Recebido em 09/03/2006

Aceito para publicação em 28/05/2006

Conflito de interesse: nenhum

Fonte de financiamento: nenhuma

\section{Como citar este artigo:}

Maciel LC, Salán FO, Guisard GC. Obstrução intestinal por volvo de ceco: relato de caso. Rev Col Bras Cir. [periódico na Internet] 2009; 36(1). Disponível em URL: http://www.scielo.br/rcbc

\section{Endereço para correspondência:}

Luiz Carlos Maciel

E-mail: luizmaciel@unitau.br 